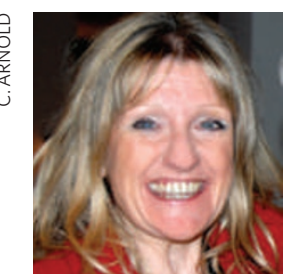

\title{
Q\&A: Bird behaviour, Darwin and dance
}

\author{
Nicky Clayton, a biologist and psychologist who studies the behaviour of birds, and who is \\ also a salsa and tango dancer, collaborated with Rambert Dance Company to create a work \\ commemorating Charles Darwin. As The Comedy of Change tours the United Kingdom, she \\ explains how communicating via motion is common to both dance and the natural world.
}

\begin{abstract}
Why celebrate evolution through dance? I am fascinated by the showy displays of clever birds, and their extravagant and elegant dances. As Rambert Dance Company's scientific adviser, my challenge was to distil Darwinian ideas to inspire movement, expressive energy and musicality. I did this by combining my knowledge of evolution with my research on the cognitive capacities of corvids - the crows and jays and my passion for dance.
\end{abstract}

\section{What does the performance convey?}

This beautiful contemporary dance that Mark Baldwin choreographed is foremost a piece of creative art. It doesn't aim to explain Darwin's theories but it may inspire audiences to think about the biology of change, the beauty of the natural world and our place in it.

We focused on three apparently paradoxical features of the biology of change: how similarities within species become differences through variation; how the future becomes the past; and how the natural world can conceal and yet reveal through camouflage and display. These principles allow females to be particular in their choice of males - and also explain why change can be so comical. The inspiration came from watching birds dance.

\section{How did the Rambert dancers respond to these evolutionary ideas?}

Artistic director and choreographer Mark Baldwin and I face the same challenge - how to communicate in the absence of language. To do so, we rely on movements, expressive energy and the dynamics of behavioural displays. The main difference is that my subjects have feathers and no hands. I gave a lecture about Darwinian ideas, and Mark and I did some tango moves afterwards in the studio with the dancers. We conveyed examples of birds dancing, from the synchronized movements of the rooks to the mating dances of male blue manakins and birds of paradise. I also showed them the camouflage displays of octopus, and how one side of the octopus can signal 'keep out' while the other flirts with a female. I drew a number of analogies with dance. For example, as a follower, I could be dancing tango with one man while another creeps up behind to steal me away - an example of male-male competition in sexual selection if ever I saw one.

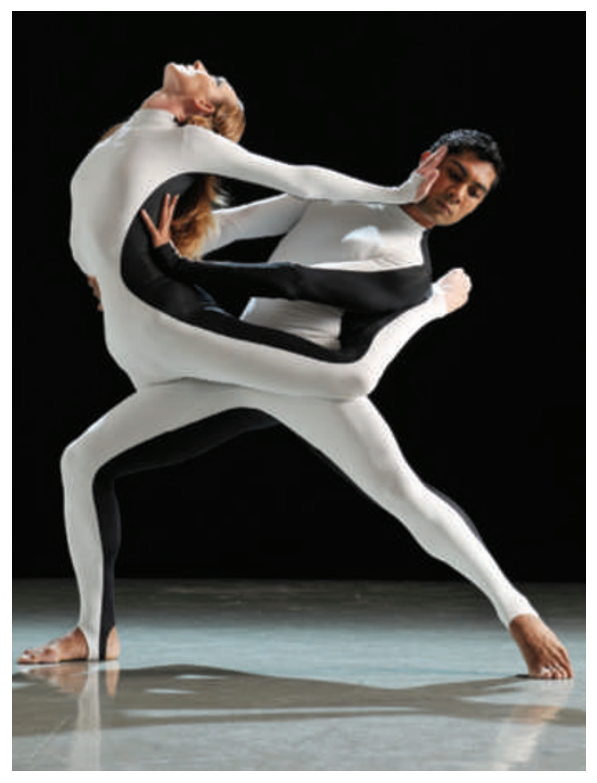

Which birds inspired you most?

One of the most impressive is the male blue manakin, which can be found in the forests of Argentina. It spends $90 \%$ of its waking day, for most of the year, in a dancing duel. Its dancing skills matter: females mate only with the best and most expert male dancers. I call it an 'avian tango'; in Argentina, tango was originally danced by pairs of men, and similarly, in blue manakins, an
ader and an apprentice follower

Darwin200 expert leader and an apprentic
perform a male double act.

Practice is critical: the young birds start when they are two years old, but they do not become an apprentice until they are about eight. Only when the senior male dies may they become the leader.

Despite the male bird's colourful plumage, he is easily concealed in the forest undergrowth. It is only when he dances that his true colours are revealed.

Even more impressive are the western parotia males, which have an 'inflatable tutu' that they use when wooing the ladies, along with the most amazing head and neck isolation movements. In this case of 'now you see it, now you don't', the idea of conceal and reveal comes to the fore. The birds also need years of experience to become the principal male.

\section{How important is coordinated movement} in the natural world?

It is very important. You see synchronicity, connection and coordination in the movements of a pair of corvids. These birds tend to pair for life, and maintaining relationships cannot be easy.

I wonder whether these synchronous movements help to cement the pair bond between the two birds, signalling commitment, connection and coordination. This might be especially important in longlived, large-brained animals that practise long-term serial monogamy - which is true of both the corvids and many human societies.

\section{Do birds respond to music?}

Yes, sound and vision are crucial in the bird world, from the showy dancing displays of the birds of paradise to the melodious songs and rich composition of the lyrebird. So it comes as no surprise that vocal-learning birds, which have their sensory apparatus attuned, have provided examples of song learning and of dancing in time to human music.

Three famous case studies of dancing to the beat are Alex the African grey parrot and cockatoos called Snowball and Frostie. And next time you hear the third movement of Mozart's Piano Concerto No. 17 in G, K. 453, think of the composer and his pet starling: Mozart taught the bird to sing the opening theme.

Interview by Patrick Goymer, associate editor at Nature.

See www.nature.com/darwin/index.html for more on Darwin. 